\title{
NOVA ESTRATÉGIA DE PREPARAÇÃO DE NANOPARTÍCULAS LIPÍDICAS SÓLIDAS PARA ENCAPSULAÇÃO DE COMPOSTOS HIDROFÍLICOS
}

\author{
L. B. PERES ${ }^{1}$, L. B. PERES ${ }^{1}$, P. H. H. ARAÚJO ${ }^{1}$, C. SAYER ${ }^{1}$ \\ ${ }^{1}$ Universidade Federal de Santa Catarina, Departamento de Engenharia Química e \\ Engenharia de Alimentos \\ E-mail para contato: csayer@enq.ufsc.br
}

\begin{abstract}
RESUMO - Nanopartículas carreadoras de fármacos apresentam-se como um método promissor para administração de medicamentos de forma segura com uma liberação prolongada e sustentada. A nanoencapsulação de fármacos apresenta meios de promover o aumento da biodisponibilidade do fármaco, a maximização de sua atividade in vivo e o alívio dos efeitos colaterais. Contudo, a encapsulação de fármacos hidrofílicos com elevada eficiência de encapsulação ainda permanece um desafio principalmente devido à forte tendência do fármaco em migrar para a fase aquosa. Assim, este trabalho propõe a preparação de nanopartículas lipídicas sólidas de ácido esteárico para encapsulação de fármacos hidrofílicos através de uma nova estratégia de preparação não exigente de solventes orgânicos baseada em uma adaptação das técnicas de dupla emulsificação e fusão-emulsificação. Os resultados obtidos mostram que é possível obter dispersões estáveis de nanopartículas com diâmetro médio entre 270 e $550 \mathrm{~nm}$ sendo o tipo e concentração de surfactante e a concentração de lipídio os fatores que mais exerceram influência sobre o tamanho final de partícula. Análises de microscopia de fluorescência, aliado a análises de absorbância por espectrofotometria UV-vis sugerem que as nanopartículas obtidas apresentam potencial aplicabilidade na encapsulação de compostos hidrofílicos de baixa massa molar.
\end{abstract}

\section{INTRODUÇÃO}

Um número crescente de trabalhos vem mostrando a potencial aplicabilidade de novos sistemas nanoestruturados para encapsulação e liberação sustentada de fármaco. Ainda que os métodos convencionais de dosagem de fármacos (pílulas, injeções, spray, etc.) tenham eficácia comprovada, o direcionamento destes compostos para o sítio de ação específico ainda é uma das principais limitações da indústria farmacêutica e biotecnológica (PARVEEN et al., 2012). De modo geral, quando administrado pelos métodos convencionais de terapêutica farmacológica, apenas uma fração da dose do fármaco é realmente aproveitada, geralmente porque o medicamento foi removido do sistema antes de atingir seu alvo (UCHEGBU; SCHATZLEIN, 2006). A encapsulação de fármacos em nanopartículas poliméricas e lipídicas sólidas apresenta meios de contornar este obstáculo através de uma liberação prolongada e proteção contra degradação prematura do fármaco, promovendo o aumento da estabilidade do fármaco e de sua biodisponibilidade (ALLEN; CULLIS, 2004; HATEFI; AMSDEN, 2002; PANYAM; LABHASETWAR, 2003). 
Os métodos de obtenção das nanopartículas são vários e sua escolha reside no tipo de material empregado e nas características físico-químicas do fármaco que deverá ser encapsulado. Substâncias hidrofílicas e hidrofóbicas podem ser encapsuladas em nanopartículas poliméricas e lipídicas, contudo, a encapsulação de fármacos hidrofílicos com elevada eficiência ainda permanece um desafio, principalmente pela falta de afinidade entre o fármaco e o polímero (ou lipídio), geralmente lipofílico, e pela tendência do fármaco em migrar para a fase aquosa durante o processo de preparação, em especial aqueles de baixa massa molar (ALMEIDA; SOUTO, 2007; LASSALLE; FERREIRA, 2007; MÜLLER et al., 2000; RAO; GECKELER, 2011).

Baseada nos princípios de duas técnicas bem estabelecidas para preparação de micronanopartículas lipídicas sólidas, a fusão-emulsificação e a dupla emulsificação, a técnica de fusão/dupla emulsificação tem demonstrado elevada eficácia na encapsulação de compostos hidrofílicos de alta massa molar em micropartículas lipídicas (BODMEIER et al., 1992; REITHMEIER et al., 2001), sendo bastante atrativa por sua formulação livre de solventes orgânicos. Contudo, até onde vai o conhecimento deste grupo de pesquisa, a adaptação desta técnica para preparação de partículas de tamanho submicrométrico e encapsulação de compostos hidrofílicos de baixa massa molar ainda não foi estudada. Assim, o objetivo deste trabalho foi explorar as variáveis de formulação da preparação de nanopartículas lipídicas sólidas de ácido esteárico através da técnica de fusão/dupla emulsificação sobre a estabilidade das miniemulsões, distribuição de tamanho de partícula e eficiência de encapsulação de compostos hidrofílicos de baixa massa molar.

\section{EXPERIMENTAL}

\subsection{Materiais}

Foram utilizados ácido esteárico (Vetec, puro), Triglicerídeos de Ácido Cáprico/Caprílico (Crodamol GTCC, Alpha Química) como lipídios para preparação das nanopartículas lipídicas sólidas. Como surfactante: Lecitina (Alfa Aesar), polioxietileno-20sorbitano monooleato (Tween 80, Vetec), sorbitano monooleato (Span 80, Oxiteno), Poloxamer 407 (Pluronic F127, Sigma-Aldrich) e Polirricinoleato de Poliglicerol (PGPR, Dhaymers). Como marcadores fluorescentes hidrofílico e hidrofóbico foram utilizados Sulfurodamina 101 (SR 101, Sigma-Aldrich) e 6-Coumarin (Sigma-Aldrich), respectivamente. Todos os reagentes foram usados como recebidos e a água empregada como fase contínua foi destilada.

\subsection{Preparação das Nanopartículas Lipídicas Sólidas}

As nanopartículas lipídicas sólidas (NLS) foram preparadas via técnica de fusão/dupla emulsificação de acordo com o procedimento descrito por Reithmeier et al. (2001) com algumas modificações necessárias para obtenção de partículas submicrométricas. Em seu estudo, Reithmeier et al. (2001) utilizaram-se de agitação mecânica para obter micropartículas lipídicas por fusão/dupla emulsificação. Assim, um dos principais ajustes necessários para obtenção de partículas na escala nanométrica, foi a substituição da agitação mecânica por um processo de sonicação. Assim, a primeira emulsão (água em óleo) foi preparada a partir da emulsificação de $0,2-0,6 \mathrm{~mL}$ de água destilada em $0,3-0,9 \mathrm{~g}$ de lipídio fundido a $72^{\circ} \mathrm{C}$ na 
presença de um surfactante de baixo HLB com auxilio de uma sonda de ultrassom acoplada a uma ponteira de 1/8' durante 15 segundos sob amplitude de $45 \%$ (20 W). Em seguida, $6 \mathrm{~mL}$ de uma solução aquosa de surfactante de alto HLB, à mesma temperatura do lipídio fundido, foi adicionada à primeira emulsão e sonicada durante 60 segundos em um regime de pulso de $15 \mathrm{~s}$ de sonicação e $5 \mathrm{~s}$ de pausa, com amplitude de $45 \%$ (segunda emulsão,água em óleo em água). Para promover a rápida solidificação do lipídio, a dupla emulsão foi adicionada à 90 $\mathrm{mL}$ de água destilada resfriada a $2{ }^{\circ} \mathrm{C}$ sob agitação. Em alguns experimentos, foi utilizado uma mistura de lipídios de ácido esteárico com Crodamol. Quando utilizado, o corante fluorescente hidrofóbico 6-coumarin (verde) foi previamente diluído em Crodamol e adicionado à fase orgânica antes da primeira etapa de sonicação. $\mathrm{O}$ corante fluorescente hidrofílico SR 101 (vermelho), por sua vez, foi diluído em água destilada e a solução foi adicionada como fase aquosa interna. A Tabela 1 mostra as formulações básicas adotadas na preparação das NLS de ácido esteárico com diferentes tipos e concentrações de surfactantes.

Tabela 1 - Formulações básicas das nanopartículas lipídicas sólidas de ácido esteárico preparadas utilizando diferentes tipos e concentrações de surfactante.

\begin{tabular}{|c|c|c|c|c|c|}
\hline \multirow{2}{*}{ Amostra } & \multirow{2}{*}{$\begin{array}{c}\text { Ácido } \\
\text { Esteárico } \\
\text { (g) }\end{array}$} & \multirow{2}{*}{$\begin{array}{l}\text { Fase Aquosa } \\
\text { Interna (mL) }\end{array}$} & \multirow{2}{*}{$\begin{array}{c}\text { Surfactante } \\
\left(1^{\mathrm{a}}\right) /\left(2^{\mathrm{a}} \text { emulsão }\right)\end{array}$} & \multicolumn{2}{|c|}{ Concentração Surfactante } \\
\hline & & & & (g) & $(\%)^{* *}$ \\
\hline Lec-T80-1/5 & \multirow{4}{*}{0,6} & \multirow{4}{*}{0,2} & \multirow{4}{*}{ Lecitina/Tween 80} & $0,006 / 0,030$ & $1 / 5$ \\
\hline Lec-T80-1/10 & & & & $0,006 / 0,060$ & $1 / 10$ \\
\hline Lec-T80-5/10 & & & & $0,030 / 0,060$ & $5 / 10$ \\
\hline Lec-T80-10/10 & & & & $0,060 / 0,060$ & $10 / 10$ \\
\hline Lec-Plu-1/5 & \multirow{3}{*}{0,6} & \multirow{3}{*}{0,2} & \multirow{3}{*}{ Lecitina/ Pluronic F127 } & $0,006 / 0,030$ & $1 / 5$ \\
\hline Lec-Plu-1/10 & & & & $0,006 / 0,060$ & $1 / 10$ \\
\hline Lec-Plu-1/20 & & & & $0,006 / 0,120$ & $1 / 20$ \\
\hline S80-T80-1/10 & \multirow{3}{*}{0,6} & \multirow{3}{*}{0,2} & \multirow{3}{*}{ Span 80/Tween 80} & $0,006 / 0,060$ & $1 / 10$ \\
\hline S80-T80-5/10 & & & & $0,030 / 0,060$ & $5 / 10$ \\
\hline S80-T80-10/10 & & & & $0,060 / 0,060$ & $10 / 10$ \\
\hline PGPR-T80-1/10 & \multirow{3}{*}{0,6} & \multirow{3}{*}{0,2} & \multirow{3}{*}{ PGPR/Tween 80} & $0,006 / 0,060$ & $1 / 10$ \\
\hline PGPR-T80-5/10 & & & & $0,030 / 0,060$ & $5 / 10$ \\
\hline PGPR-T80-10/10 & & & & $0,060 / 0,060$ & $10 / 10$ \\
\hline
\end{tabular}

* (1 $1^{\mathrm{a}}$ emulsão $) /\left(2^{\mathrm{a}}\right.$ emulsão $)$

** porcentagem em massa de surfactante em relação ao lipídio (surfactante $1(\%) /$ surfactante $2(\%)$ )

O diâmetro médio (Dp) e índice de polidispersão (PDI) das nanopartículas foram determinados através da técnica de Espalhamento Dinâmico de Luz (DLS - Zetasizer Nano ZS 3600, Malvern Instruments). A morfologia das nanopartículas foi determinada através da técnica de Microscopia Eletrônica de Transmissão (MET - JSM-1011, JEOL) utilizando contraste negativo de acetato de uranila. A encapsulação dos marcadores fluorescentes foi avaliada através da técnica de Microscopia de Fluorescência (microscópio epifluorescente invertido Olympus, Bx41). As amostras foram observadas com lente objetiva de 100x e utilizando os filtros vermelho (U-MGW2) para o corante fluorescente SR $101\left(\lambda_{\text {abs }}=580 \mathrm{~nm}\right.$ e $\left.\lambda_{\mathrm{em}}=600 \mathrm{~nm}\right)$ e verde $(\mathrm{U}-\mathrm{MWB} 2)$ para o corante fluorescente 6 -coumarin $\left(\lambda_{\mathrm{abs}}=458 \mathrm{~nm} \mathrm{e}\right.$ $\lambda_{\text {em }}=505 \mathrm{~nm}$ ). A eficiência de encapsulação (EE) do marcador fluorescente hidrofílico foi determinada através de espectroscopia UV-vis (Micronal, AJX-1900), utilizando uma curva de calibração como referência no comprimento de onde de $586 \mathrm{~nm}$. A quantidade de corante hidrofílico presente na fase aquosa da miniemulsão (corante não encapsulado) foi determinada 
pela ultrafiltração de $500 \mu \mathrm{L}$ de dispersão de nanopartículas em Amicon Ultra-0.5 (Millipore, $100 \mathrm{KDa}$ - $100.000 \mathrm{NMWL}$ ) a $13.400 \mathrm{rpm}$. Os cálculos foram realizados levando em consideração a quantidade total de corante adicionada a formulação.

Todos os experimentos foram realizados em triplicata ou mais, sendo apresentado a média e o desvio padrão (DP) para os valores de Dp e PDI.

\section{RESULTADOS E DISCUSSÃO}

\subsection{Efeito do tipo e concentração de surfactante}

Segundo Khoee e Yaghoobian (2009) e Pal (2007), a combinação de surfactantes hidrofílicos e lipofílicos na preparação de nanopartículas por dupla emulsificação é importante do ponto de vista de estabilização das nanopartículas e de aumento da eficiência de encapsulação de compostos hidrofílicos. Com isso em mente, quatro pares de surfactantes foram utilizados: Lecitina e Tween 80, Lecitina e Pluronic F127, Span 80 e Tween 80 e PGPR e Tween 80, sendo a lecitina anfótera e lipofílica, o Span 80 e o PGPR não-iônicos e lipofílicos e o Tween 80 e Pluronic F127 não-iônicos e hidrofílicos. Os resultados das miniemulsões preparadas utilizando as diferentes combinações e concentrações de surfactantes, bem como o acompanhamento da estabilidade das miniemulsões ao longo de 60 dias, estão apresentados na Figura 1. Em todos os experimentos foram utilizados 0,6 g de ácido esteárico, 0,2 $\mathrm{mL}$ de fase aquosa interna, 6,0 $\mathrm{mL}$ de fase aquosa externa e $90 \mathrm{~mL}$ de fase aquosa de solidificação $\left(2^{\circ} \mathrm{C}\right)$.

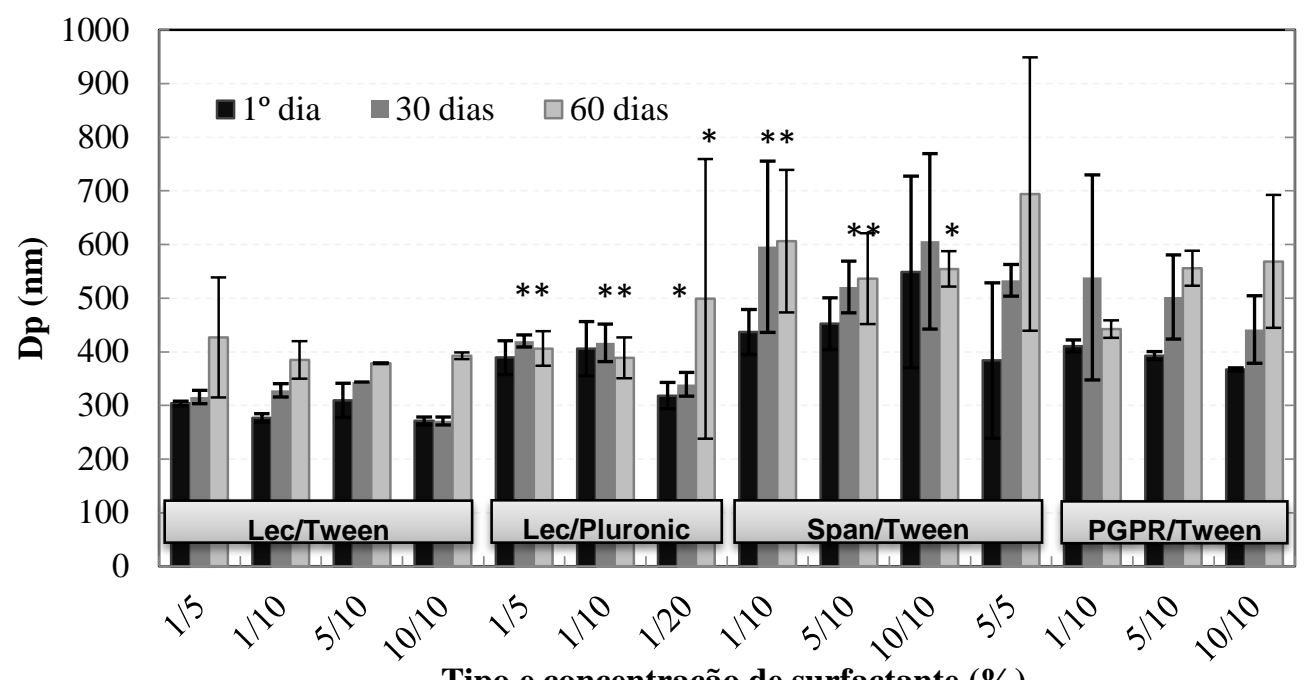

Tipo e concentração de surfactante $(\%)$

Figura 1 - Efeito do tipo e concentração de surfactante sobre Dp e PDI das nanopartículas de ácido esteárico (Média \pm DP, $n \geq 3$ ) e estudo da estabilidade das miniemulsões de NLS estocadas a $4^{\circ} \mathrm{C}$ (Média $\pm \mathrm{DP}, \mathrm{n} \geq 2$ ). *Pelo menos uma das miniemulsões apresentou formação de precipitado.

É possível observar que todos os sistemas analisados resultaram em partículas na escala submicrométrica. As quatro combinações de surfactantes avaliadas apresentaram diferentes eficiências de estabilização e, consequentemente, diferentes tamanhos médios de partícula e índice de polidispersão. Os menores diâmetros médios de partícula foram obtidos quando 
utilizado o par Lecitina/Tween 80. Por outro lado, as maiores partículas foram obtidas quando utilizado o par Span 80/Tween 80. A agregação das partículas e um subsequente aumento do tamanho médio de partícula foi observado em todas as amostras ao longo dos 60 dias do estudo. Durante este período, algumas amostras perderam a estabilidade e houve a formação de precipitado (representado com um asterisco (*) na Erro! Fonte de referência não encontrada.). Os resultados obtidos sugerem que, de maneira semelhante ao reportado na literatura (BUMMER, 2004; KHERADMANDNIA et al., 2010), a combinação dos efeitos estabilizantes estérico e eletrostático garante uma melhor estabilização da dispersão e minimiza a agregação das nanopartículas.

As imagens obtidas por microscopia eletrônica de transmissão (MET) das nanopartículas de ácido esteárico preparadas utilizando o par Lecitina/Tween 80 na concentração de 1/10 estão apresentadas na Figura . Apesar do recobrimento das amostras com filme de carbono antes das análises de MET, não foi possível evitar a fusão do lipídio sob o feixe de elétrons, como pode ser observado na Figura, dificultando bastante a análise acerca da morfologia da partícula (nanoesfera ou nanocápsula). Durante as análises de MET foi possível observar um rápido aumento do tamanho de partícula durante os primeiros segundos da incidência do feixe de elétrons devido a fusão do lipídio. A partir deste ponto, o tamanho de partícula manteve-se estável (não aumentou ou diminuiu) independentemente do tempo de exposição ao feixe. Isto indica que o tamanho das partículas observadas nas imagens da Figura 2 é ligeiramente maior do que o real, uma vez que foram registradas após a estabilização do tamanho de partícula. Ainda assim, a grande maioria das partículas encontram-se na faixa de tamanho submicrométrica como indicado pelo análise de DLS
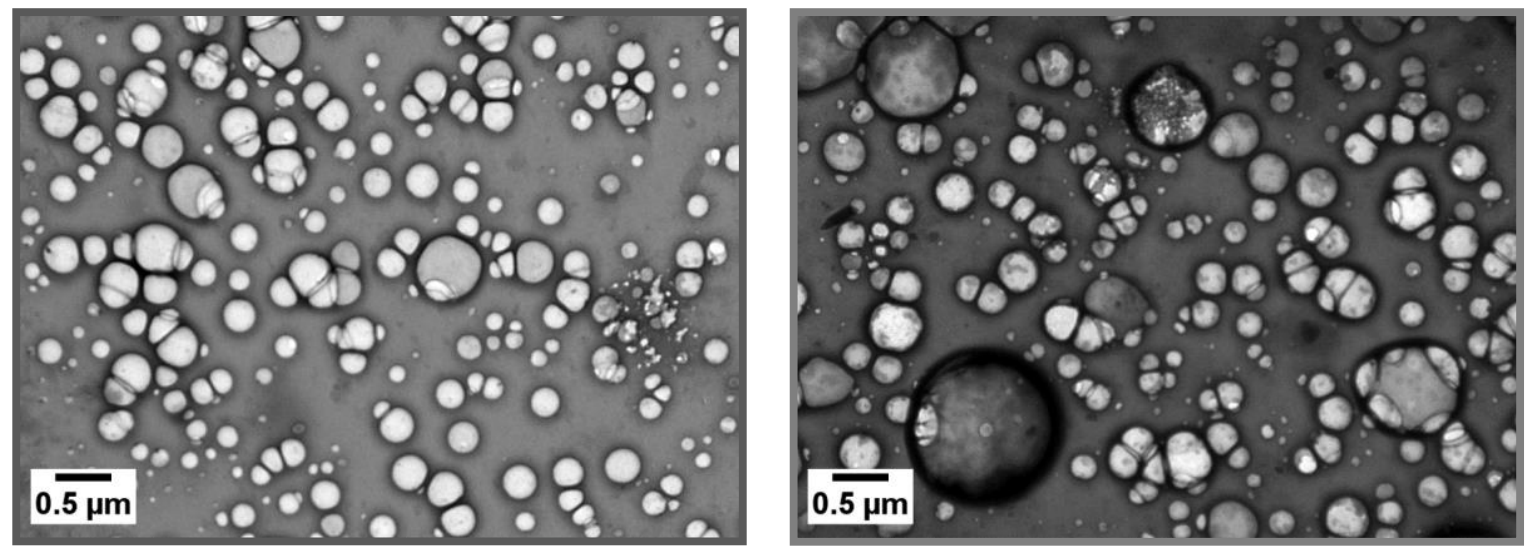

Figura 2 - Imagens de MET das nanopartículas de ácido esteárico preparadas com o par Lectina/Tween na concentração de 1/10.
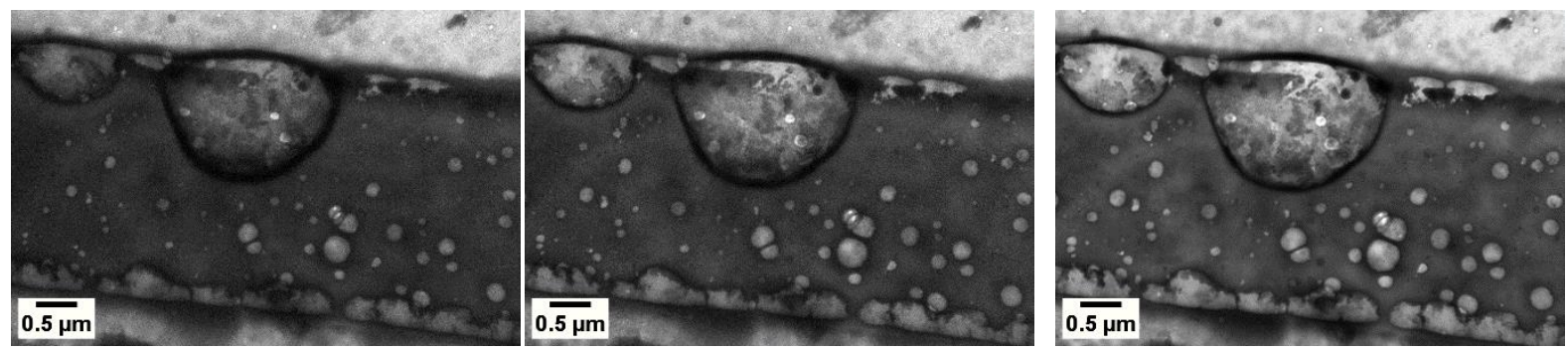

Figura 3 - Imagens de MET da modificação das nanopartículas de ácido esteárico com o feixe de elétrons $(80 \mathrm{kV})$. 


\subsection{Efeito da concentração de lipídio e do fator de Diluição/Solidificação}

O efeito da concentração de lipídio e do volume da fase aquosa de Diluição/ Solidificação (água destilada resfriada a $2^{\circ} \mathrm{C}$ ) sobre o Dp e PDI das nanopartículas lipídicas de ácido esteárico também foi avaliado. Os resultados obtidos estão apresentados nas Figura a e 4b. Os experimentos foram realizados utilizando $6,0 \mathrm{~mL}$ de fase aquosa externa, $90 \mathrm{~mL}$ de fase aquosa de diluição/solidificação (quando não mencionado de outra forma) e o par Lecitina/Tween 80 na concentração de 1/10.

a)

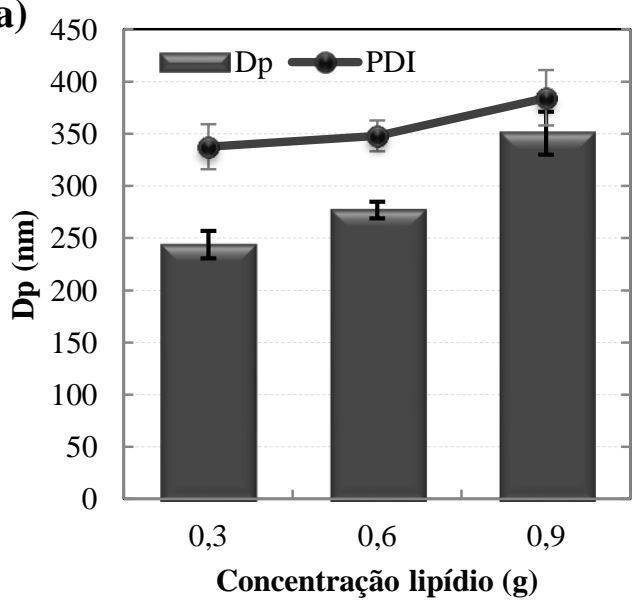

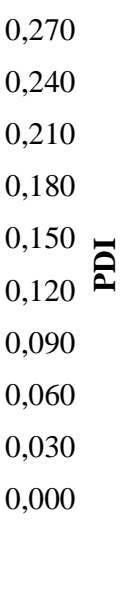

b)

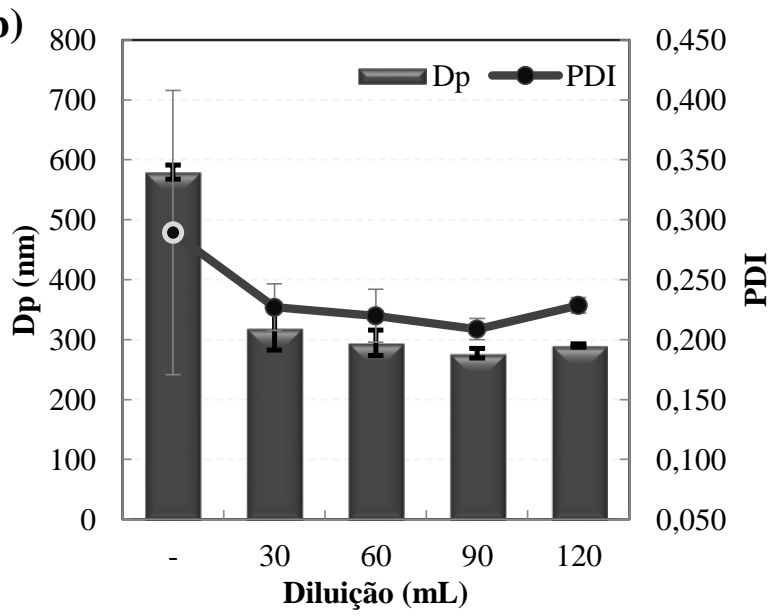

Figura 4 - Efeito (a) da concentração de lipídio e (b) do volume da fase aquosa de Diluição/

Solidificação sobre Dp e PDI das nanopartículas de ácido esteárico (Média \pm DP, $n \geq 3$ ).

Como era esperado, o aumento da concentração de lipídio resultou no aumento do tamanho final de partícula e em distribuições de tamanho de partícula mais largas. É possível afirmar que o comportamento observado está diretamente relacionado com o aumento do volume da primeira emulsão. Devido a um aumento da relação fase dispersa/fase contínua, houve um incremento dos mecanismos de degradação da segunda emulsão e, consequentemente, a um aumento do tamanho das NLS formadas.

O aumento do volume da fase aquosa de diluição/solidificação de 30 para $120 \mathrm{~mL}$, por sua vez, não exerceu efeito significativo sobre o tamanho da partícula e índice de polidispersão. No entanto, quando a solidificação do lipídio foi promovida sem diluição, através de agitação sob temperatura reduzida (banho de gelo), um grande aumento de Dp e PDI foi observado. O aparente mecanismo responsável por este fenômeno é o aumento da proximidade entre as partículas recém-formadas e o maior tempo dado para as gotas solidificarem, o que acabou favorecendo o processo de coalescência.

\subsection{Eficiência de Encapsulação}

Um dos grandes desafios da dupla emulsificação é a instabilidade termodinâmica de emulsões inversas, principalmente na escala nanométrica. Em virtude da grande quantidade de energia cedida ao sistema durante o processo de sonicação, existe uma forte tendência à ruptura das gotas de água e quebra da primeira emulsão durante o processo de obtenção da segunda emulsão, o que acabaria levando à formação de uma emulsão simples (nanoesferas) ao invés de uma emulsão dupla (nanocápsulas com núcleo aquoso) e resultando em uma baixa 
eficiência de encapsulação.

A encapsulação de compostos hidrofílicos de baixa massa molar foi avaliada através da encapsulação simultânea de dois marcadores fluorescentes: um hidrofílico (vermelho) e outro hidrofóbico (verde). As imagens obtidas por microscopia de fluorescência estão apresentadas na Figura . Para fins de controle foram preparadas nanopartículas sem marcador e com ambos os corantes encapsulados separadamente, e não foi encontrada nenhuma interferência (dados não mostrados). Todos os experimentos foram realizados utilizando 0,6 g de lipídio (ácido esteárico + crodamol), 0,2 mL e 6,0 mL de fase aquosa interna e externa, respectivamente, 90 $\mathrm{mL}$ de solução aquosa de diluição/solidificação e o par Lecitina/Tween 80 na concentração de 1/10. Devido à baixa magnificação alcançada pelo microscópio (aumento de 100x), apenas ficaram visíveis as maiores partículas, com $\mathrm{Dp}>1 \mu \mathrm{m}$. As partículas menores, nanométricas, apenas tornam-se visíveis através da manipulação das imagens (com auxílio de um software) através do aumento da magnificação e do contraste (imagens em detalhe). Contudo, isto acaba resultando na saturação do vermelho, prejudicando a qualidade da imagem. A Figura 5 mostra as mesmas partículas sob efeito de diferentes filtros: o vermelho, para o corante fluorescente hidrofílico SR 101, e o verde, para o corante fluorescente lipofílico 6-coumarin. Pode-se observar que as nanopartículas que brilham em verde na primeira imagem, também brilham em vermelho na segunda, indicando que houve a encapsulação do corante hidrofílico. A determinação da eficiência de encapsulação por espectrofotometria UV-vis mostrou que aproximadamente $61 \% \pm 6.4$ do corante hidrofílico adicionado à formulação foi encapsulado.
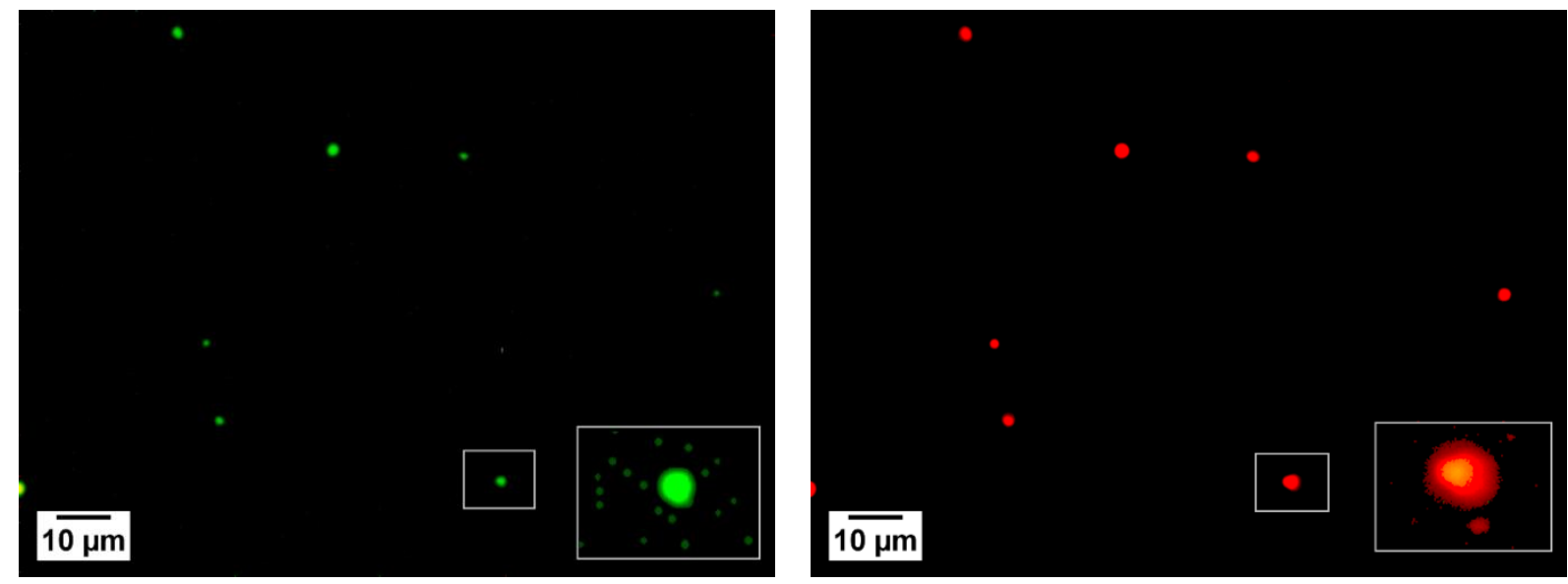

Figura 5 - Imagens obtidas por microscopia de fluorescência de nanopartículas lipídicas preparadas com a incorporação simultânea do marcador hidrofílico (SR-101) e lipofílico (6coumarin). Na ordem: microscopia sem fluorescência, com fluorescência filtro verde e com fluorescência filtro vermelho.

\section{CONCLUSÕES}

Os resultados obtidos mostram que é possível obter nanopartículas lipídicas sólidas de ácido esteárico com potencial aplicabilidade para encapsulação de fármacos hidrofílicos utilizando a técnica de fusão/dupla emulsificação na ausência de solventes orgânicos. $O$ estudo da influência dos parâmetros de processo permitiu verificar que é possível obter dispersões estáveis de nanopartículas com diâmetro médio entre 270 e $550 \mathrm{~nm}$ através do ajuste das formulações e condições experimentais. 


\section{AGRADECIMENTOS}

Ao CNPq - Conselho Nacional de Pesquisa e Desenvolvimento Científico e Tecnológico pelo apoio financeiro e aos Laboratórios Multiusuários de Estudos em Biologia (LAMEB II) e Central de Microscopia Eletrônica (LCME) da Universidade Federal de Santa Catarina (UFSC).

\section{REFERÊNCIAS}

ALLEN, T. M.; CULLIS, P. R. Drug delivery systems: entering the mainstream. Science, v. 303, p. 1818-22, 2004.

ALMEIDA, A. J.; SOUTO, E. Solid lipid nanoparticles as a drug delivery system for peptides and proteins. Adv. Drug Delivery Rev., v. 59, p. 478-90, 2007.

BODMEIER, R.; WANG, J.; BHAGWATWAR, H. Process and formulation variables in the preparation of wax microparticles by a melt dispersion technique. II. W/O/W multiple emulsion technique for water-soluble drugs. J. Microencapsul., v. 9, p. 99-107, 1992.

BUMMER, P. M. Physical chemical considerations of lipid-based oral drug delivery--solid lipid nanoparticles. Crit. Rev. Ther. Drug, v. 21, p. 1-20, 2004.

HATEFI, A; AMSDEN, B. Biodegradable injectable in situ forming drug delivery systems. J. Control. Release, v. 80, p. 9-28, 2002.

LASSALLE, V.; FERREIRA, M. L. PLA nano- and microparticles for drug delivery: an overview of the methods of preparation. Macromol. Biosci., v. 7, p. 767-83, 2007.

KHERADMANDNIA, S. et al. Preparation and characterization of ketoprofen-loaded solid lipid nanoparticles made from beeswax and carnauba wax. Nanomed-naotechnol., v. 6, p. 753-9, 2010.

KHOEE, S.; YAGHOOBIAN, M. An investigation into the role of surfactants in controlling particle size of polymeric nanocapsules containing penicillin-G in double emulsion. Eur. J. Med. Chem., v. 44, p. 2392-9, 2009.

MÜLLER, R. H.; MÄDER, K.; GOHLA, S. Solid lipid nanoparticles (SLN) for controlled drug delivery - a review of the state of the art. Eur. J. Pharm. Biopharm., v. 50, p. 161-77, 2000.

PAL, R. Rheology of double emulsions. J. Colloid Interf. Sci., v. 307, p. 509-15, 2007.

PANYAM, J.; LABHASETWAR, V. Biodegradable nanoparticles for drug and gene delivery to cells and tissue. Adv. Drug Delivery Rev., v. 55, p. 329-347, 2003.

PARVEEN, S.; MISRA, R.; SAHOO, S. K. Nanoparticles: a boon to drug delivery, therapeutics, diagnostics and imaging. Nanomed-Nanotechnol., v. 8, p. 147-66, 2012.

RAO, J. P.; GECKELER, K. E. Polymer nanoparticles: Preparation techniques and size-control parameters. Prog. Polym. Sci., v. 36, p. 887-913, 2011.

REITHMEIER, H.; HERRMANN, J.; GÖPFERICH, A. Lipid microparticles as a parenteral controlled release device for peptides. J. Control. Release, v. 73p. 339-50, 15, 2001.

UCHEGBU, I. F.; SCHATZLEIN, A. G. Polymers in Drug Delivery. United States: CRC Press, 2006.

ZAMBAUX, M. F. et al. Influence of experimental parameters on the characteristics of poly(lactic acid) nanoparticles prepared by a double emulsion method. J. Control. Release, v. 50, p. 31-40, 1998. 